\title{
Assessment of prescribing trends for rational use of drugs
}

\author{
Sonali B. Rode ${ }^{1}$, Harsh V. Salankar ${ }^{1 *}$, Gyaneshwar Mishra ${ }^{2}$, Shashank Mishra ${ }^{2}$
}

${ }^{1}$ Department of Pharmacology, Shri Shankaracharya Institute of Medical Sciences, Bhilai, Chhattisgarh, India

${ }^{2}$ Department of Surgery, Chirayu Medical College and Hospital, Bhopal, Madhya Pradesh, India

Received: 27 June 2018

Accepted: 26 July 2018

\section{*Correspondence to:}

Dr. Harsh V. Salankar,

Email: harshsalankar@ gmail.com

Copyright: (C) the author(s), publisher and licensee Medip Academy. This is an openaccess article distributed under the terms of the Creative Commons Attribution NonCommercial License, which permits unrestricted noncommercial use, distribution, and reproduction in any medium, provided the original work is properly cited.

\begin{abstract}
Background: Nowadays irrational use of drugs is a major problem inspite of extensive programs being carried out on rational use of medicines. Therefore, in present study we evaluated OPD prescriptions for rationality and their adherence to prescription format.

Methods: A prospective, observational study was carried out in 511 outdoor patients for a period of three months. Quality of prescription writing was assessed for completeness of information and legibility. Rationality was analyzed using WHO core prescribing indicators.

Results: Basic information of patient and name of department were written in all the prescriptions. Diagnosis was mentioned in $76.33 \%$ cases. Dosage forms, dose, frequency and duration of treatment were mentioned in $97.26 \%, 73 \%, 80.04 \%$ and $80.23 \%$ of prescriptions respectively. About $73.78 \%$ prescriptions were legible. Doctor's name, signature and registration number were present in $80.82 \%, 82.97 \%$ and $15.66 \%$. Total number of drugs in 511 cases was 1074 . Average number of drugs/ prescriptions was $2.1 \pm 0.8$. Drugs were prescribed by generic name in $25.14 \%$ cases; drugs from EDL were $57.36 \%$. Antimicrobial agents, injectable drugs and FDCs were prescribed in $25.83 \%, 12.13 \%$ and $39.14 \%$ cases. The most commonly prescribed drugs were analgesics, GIT and cardiovascular drugs.

Conclusions: This study shows possible areas of improvement in prescription practice that is generic prescribing, use of essential medicines, restraint in use of irrational fixed dose combinations and better quality of prescribing in terms of inclusiveness of information, legibility and doctor's details.
\end{abstract}

Keywords: Prescription format, Prescribing patterns, Rational drug therapy, WHO indicators

\section{INTRODUCTION}

The quality of health care, particularly the rationality in drug usage, depends on many activities such as making the correct diagnosis, prescribing the appropriate drugs in correct doses and dispensing them properly. Prescription is a written medico legal manuscript by the doctor for the treatment of patient which should contain all four components viz., superscription, inscription, subscription and signature with registration details of the prescriber. ${ }^{1}$ Prescribing errors occur if necessary information is not mentioned in prescription. ${ }^{2}$ Almost $70 \%$ medication mistakes are born due to the wrong prescriptions and prescription errors. It is necessary to define prescribing pattern and to detect the irrational prescribing customs to drive a remedial note to the prescribers.

Scrutiny of drug use within the institution and in the community is assuming an increasingly imperative role in clinical practice. ${ }^{3}$ To investigate the rational use of drugs, World Health Organization (WHO) compiled a set of core drug use indicators that are useful to study patterns of drug prescribing. ${ }^{4,5}$ The constant monitoring of prescription may help to identify the problems involved in therapeutic assessments and would thus encourage rational drug prescribing. ${ }^{6}$ 
Therefore, present study examined the pattern of drug use in outdoor patients of a tertiary care teaching hospital to investigate the prescribing manners of consultant physicians and rationalize drug use, thereby curtailing medication mistakes and improving therapeutic outcomes.

\section{METHODS}

This observational, prospective study was carried out in outdoor patients of Chirayu medical college and hospital, Bhopal for three months from October to December 2016. Prescriptions were collected from pharmacy regardless of diagnosis, age and gender across different departments of the hospital and evaluated for:

- $\quad$ Adherence to prescription format

- Rationality of prescription

\section{Adherence to prescription format}

For studying the adherence to prescription format following prescription components were noted for their correctness:

- Basic patient demographics

- Name of the department and diagnosis

- Legibility

- Completeness of prescription with regards to dose, frequency, dosage forms, duration of treatment and direction of use of drugs

- Doctor's name, signature and registration number

\section{Rationality of prescription}

Prescriptions were analyzed for the rationality by using WHO drug use indicators:

- Average number of drugs/ prescription

- $\quad$ Percentage of drugs prescribed by generic name

- Percentage encounters with an antimicrobial prescribed

- $\quad$ Percentage encounters with an injectables prescribed

- Percentage of prescriptions containing fixed dose combinations (FDC)

- $\quad$ Percentage of drugs prescribed from essential drug list (EDL)

Data was analyzed using Microsoft excel 2007.

\section{RESULTS}

Total 511 prescriptions from various departments were analyzed as shown in Figure 1.

Gender analysis revealed that males were more (53.42\%) than females $(46.58 \%)$. Most of the cases were in the age group of 41 to 50 years $(26.81 \%)$ followed by 31 to 40 years $(23.48 \%)$. Demographic characteristics of patients (name, age, sex and address) and name of department were mentioned in all prescriptions (100\%). Diagnosis was mentioned in $76.33 \%$ cases and about $73.78 \%$ prescriptions were legible. Dosage forms, dose, frequency and duration of treatment were mentioned in $97.26 \%$, $73 \%, 80.04 \%$ and $80.23 \%$ of the prescriptions respectively. Doctor's name, signature and registration number were present in $80.82 \%, 82.97 \%$ and $15.66 \%$ respectively as shown in Figure 2.

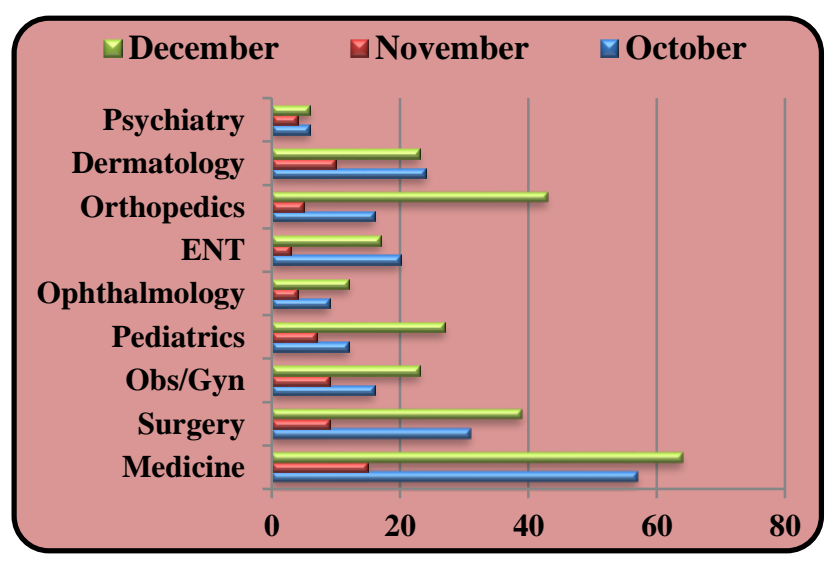

Figure 1: Department wise monthly prescription audit.

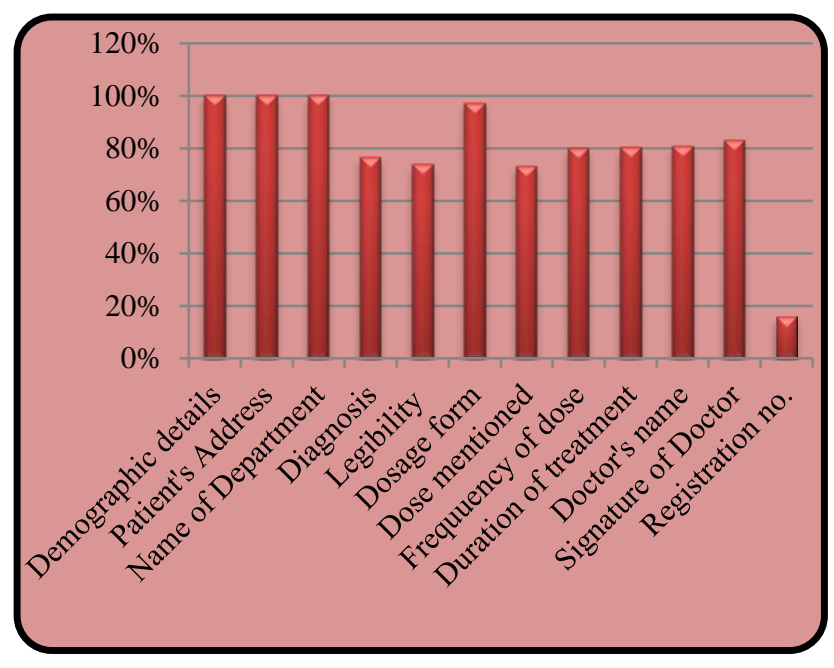

Figure 2: Prescription analysis.

Table 1 summarizes findings of the analysis using WHO drug use indicators. Total 1074 drugs were prescribed in 511 patients. Average number of drugs per prescription was $2.1 \pm 0.8$. About $25.14 \%$ of the drugs were prescribed by generic names and $57.36 \%$ drugs were from essential drug list. ${ }^{7,8}$ Antimicrobials, injectable drugs and FDC were prescribed in $25.83 \%, 12.13 \%$ and $39.14 \%$ cases respectively.

Analgesics (23\%) were most prescribed drugs followed by gastrointestinal drugs (19\%), cardiovascular drugs (18\%), antimicrobial agents (16\%), antihistaminics (9\%), antidiabetics $(6 \%)$, vitamins $(6 \%)$ and others $(3 \%)$ as shown in Figure 3. 
Table 1: Analysis of prescriptions according to WHO prescribing indicators.

\begin{tabular}{|ll|}
\hline WHO prescribing indicators & Analysis \\
\hline Average number of drugs per prescription & $2.1 \pm 0.8$ \\
\hline Percentage of drugs prescribed by generic & $270 / 1074$ \\
name & $(25.14 \%)$ \\
\hline Percentage encounters with an & $132 / 511$ \\
antimicrobial prescribed & $(25.83 \%)$ \\
\hline $\begin{array}{l}\text { Percentage encounter with an injectable } \\
\text { drug prescribed }\end{array}$ & $62 / 511$ \\
\hline Percentage of prescriptions containing & $(12.13 \%)$ \\
FDC & $200 / 511$ \\
\hline Percentage of drugs prescribed from EDL & $616.14 \%)$ \\
\hline
\end{tabular}

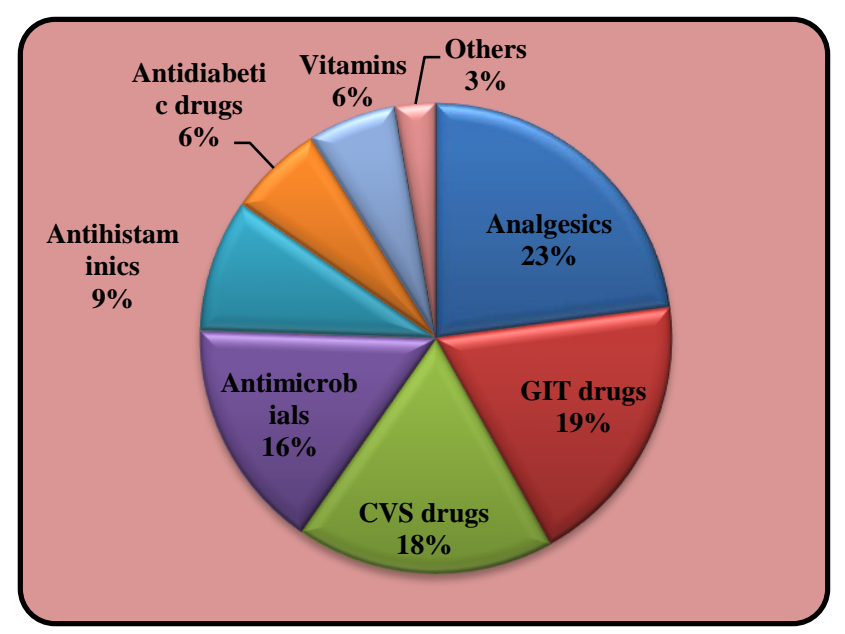

Figure 3: Common categories of drugs prescribed.

\section{DISCUSSION}

Prescription is a legal document that can be used both for safeguarding as well as defaming the physician and pharmacist in cases attributed to prescribing or dispensing inaccurancies..$^{9,10}$ Thus prescriptions require close surveillance and effective interference whenever needed. This study aimed to find out the shortcomings in prescription and investigate the prescribing behavior of consultant physicians.

In this study, basic demographic parameters like name, age, sex and complete address was mentioned in $100 \%$ prescriptions similar to report by Shelat et al. ${ }^{11}$ Study conducted at Ethopia and Dubai reported that age and gender were not mentioned in $36.6 \%, 18.6 \%$ and $9.7 \%$, $12 \%$ respectively which is higher compared to our study. ${ }^{12,13}$ Patient details like age and gender can be helpful in certain drug precautions amongst pediatric, geriatric patients and pregnant women.

Complete diagnosis was stated in $76.33 \%$ of prescriptions which is higher as compared to study by Rishi et al, $(22.25 \%)$ but lower than Siddharth et al, where it was $97 \% .{ }^{14,15}$ A brief mention about the diagnosis is useful to pharmacist to ensure that the drugs prescribed are appropriate for the patient's illness. About $73.78 \%$ of prescriptions were legible similar to study conducted at Sri lanka. ${ }^{16}$ Dispensing errors due to difficult or impossible to read prescriptions may be harmful for the patients, with legal consequences for both physician and pharmacist. ${ }^{9,17}$

In this study dosage forms were mentioned in $97.26 \%$ cases, but duration of treatment, dose and frequency were not correctly mentioned in about $20 \%$ of prescriptions which is higher compared to a study conducted at Nigeria. ${ }^{18}$ It might be due to verbal communication by the prescriber to the recipient but patient might fail to recall the instructions and increase chances of medication error. Another cause may be excessive work and shortage of time on the part of prescribers. Therefore, proper training and education of physicians is necessary regarding legibility and completeness of prescriptions in all regards.

It was observed that $80.82 \%$ prescriptions contained doctor's name with its signature $(82.97 \%)$ but registration number was mentioned only in $15.66 \%$ cases. Study conducted at Dubai ${ }^{13}$ reported that doctor's name, signature and registration number were absent in $10.3 \%$, $12.2 \%$ and $54.9 \%$ of prescription respectively. Prescription without proper medical registration details of the doctor can be the cause of concern as it may have adverse medico legal consequences.

In this study the total number of drugs in 511 prescriptions analyzed was 1074 . Therefore, average number of drugs per prescriptions was 2.1 which is very much in line to the recommended limit of 2.0. ${ }^{19}$ These findings suggest restricted incidence of polypharmacy. Upsurge in the number of average drugs per prescription may raise the risk of drug interactions, may lead to undesirable side effects and also increases the prescribing errors. However, in certain cases like cardiovascular and diabetes, patients may require more than one drug.

Only $25.14 \%$ generic drugs were prescribed. This undoubtedly shows that prescribing habits are clearly prejudiced by the activities of representative of the pharmaceutical companies. Generic prescribing lessens the risks of dispensing errors which may be due to confusion of like sounding names of drugs and also reduce the economic liability on the patient. Hence, we should boost generic prescribing by physician's education and strict obedience of WHO policies.

Majority of dosage form used was oral $84.36 \%$, injectables were $12.10 \%$, inhalational and topical forms were least i.e, $2.89 \%$ and $0.65 \%$ respectively. This is admissible as it was an OPD based prescription audit. FDCs were prescribed in large number of cases (39.14\%). Use of FDCs should be avoided unless strictly essential. It may permit incorrect use of unwanted drugs which can lead to adverse effects and drug interactions. Drugs from EDL were only $57.36 \%$, though it is analogous with other studies but still it is on 
lower side. ${ }^{20,21}$ Prescribing from EDL is a good clinical practice and rallies the rational use of medicines.

Most common categories of drugs prescribed were analgesics (23\%) followed by gastrointestinal drugs (19\%) and cardiovascular drugs (18\%).

Antimicrobials were prescribed in $25.83 \%$ cases amongst which $6.65 \%$ received more than one agent. It is acceptable, and this figure is much lower as compared to study by Gupta et al. ${ }^{22}$ Appropriate use of antibiotics is absolutely necessary to prevent emergence of drug resistance and should be formulated so that the clinicians can use them thoughtfully according to patients need.

The rationality of the script prescribed by physicians is of utmost importance, since bad prescribing habits lead to unsuccessful and unsafe treatment, causing exacerbation or prolongation of disease and distress to the patient, which adds an extra burden to the health budget.

\section{CONCLUSION}

Present study shows general trends in the prescribing habits of doctors across various departments. It indicates potential areas of improvement in prescription practice that is generic prescribing, use of essential medicines, restraint in use of irrational fixed dose combinations and better quality of prescription writing in terms of inclusiveness of information, legibility and doctor's details. Drug prescription practices in hospitals should be improved by employing institutional guidelines for appropriate prescription writing and encouraging use of the list of essential drugs. More stress needs to be laid on teaching the art of writing a prescription to undergraduate and postgraduate students.

Funding: No funding sources

Conflict of interest: None declared

Ethical approval: The study was approved by the Institutional Ethics Committee

\section{REFERENCES}

1. WHO; 2008. Sampling to Study Drug Use. 2000. Available http://archives.who.int/PRDUC2004/RDUCD/TOC.h tml(archived July 2008)

2. Lesar TS. Factors related to errors in medication prescribing. J Am Med Assoc. 1997;277(4):312.

3. Singh S, Ansari KU, Kastury N, Pandey RC. An audit of prescription for rational use of antibiotics. Indian $\mathrm{J}$ Pharmacol. 1997;18:77-81.

4. WHO. Drugs and Therapeutics Committees - A Practical Guide. Geneva: World Health Organization; 2003.

5. World Health Organization. The World Health Report 2001- Mental Health: new understanding, new hope. Geneva; 2001. Available at: http://www.who.int/whr/2001/en/. [Last accessed on 2018 May 22].

6. Ansari KU, Singh S, Pandey RC. Evaluation of prescribing patterns of doctors for rational drug therapy. Indian J Pharmacol. 1998;30:43-6.

7. WHO model list of essential medicines. Available at: http://www.who.int/medicines/publications/essential medicines/20th_EML2017_FINAL_amendedAug201 7.pdf?ua $=1$

8. National list of essential medicines of India. Ministry of Health and Family welfare. Government of India; 2015. Available at: http://cdsco.nic.in/WriteReadData/NLEM2015/NLEM,\%202015.pdf Accessed 29 May2018.

9. The Pharmaceutical Professions and Institutions. UAE Federal Law No: 4,1983.

10. Irshaid YM, Al Homrany M, Hamdi AA, AdjeponYamorah KK, Mahfouz AA. Compliance with good practice in prescription writing at outpatient clinic in Saudi Arabia. East Mediterr Health J. 2005;11(5,6):922-8.

11. Shelat PR, Kumbar SK. Analysis of Out Door Patients' Prescriptions According to World Health Organization (WHO) Prescribing Indicators Among Private Hospitals in Western India. Journal of Clinical and Diagnostic Research: JCDR. 2015;9(3):FC01FC04.

12. Desta Z, Abdulwhab M. Prescriptions writing in Gondar outpatient teaching hospital, Ethopia. East Afr Med J. 1996;73(2):115-59.

13. Sharif SI, Al-Shaqra M, Hajjar H, Shamout A, Wess L. Patterns of Drug Prescribing In A Hospital In Dubai, United Arab Emirates. Libyan J Med. 2008;3(1):10-2.

14. Rishi RK, Sangeeta S, Surendra K, Tailang M. Presecription audit: experience in Garwhwal (Uttaranchal), India. Trop Doct. 2003;33(2):64-8.

15. Siddarth V, Arya S, Gupat SK. A study of prescribing practices in outpatient department of an apex tertiary care institute of India. Int $\mathbf{J}$ Res Foundation Hosp Health Adm. 2014;2(1):31-5.

16. Prasad K, Ranasinghe B. Pattern of private sector drug prescription in Galle: A descriptive cross-sectional study. Gall Med J. 2006:64-68.

17. Brahams D. Legal liability and the negligent prescription. Practitioner. 1984;228:444-5.

18. Tamuno I, Fadre J. Drug utilization pattern in a Nigerian tertiary hospital. Trop $\mathrm{J}$ Pharm Res. 2012;11:146-52.

19. WHO. How to investigate drug use in health facilities: Selected drug use indicators. Geneva: World Health Organization;.WHO/DAP. 1993;1:1-87.

20. Biswas NR, Jindal S, Siddiquei MM, Maini R. Patterns of prescription and drug use in ophthalmology in a tertiary hospital in Delhi. Br J Clin Pharmacol. 2001;51:267-9.

21. Hazra A, Tripathi SK, Alam MS. Prescribing and dispensing activities at the health facilities of a nongovernmental organization. Natl Med $\mathbf{J}$ India. 2000;13:177-82. 
22. Gupta N, Sharma D, Garg SK, Bhargava VK. Auditing of prescriptions to study utilization of antimicrobials in a tertiary hospital. Indian $\mathrm{J}$ Pharmacol. 1997;29:411-5.
Cite this article as: Rode SB, Salankar HV, Mishra G, Mishra S. Assessment of prescribing trends for rational use of drugs. Int J Basic Clin Pharmacol 2018;7:1758-62. 